\title{
Verão do amor: os jovens e a nova forma de vestir ${ }^{[1]}$
}

\author{
Verano de amor: jóvenes y \\ la nueva forma de llevar
}

\author{
Laiana Pereira da Silveira ${ }^{[2]}$
}

\begin{abstract}
Resumo: A síntese do artigo tem como objetivo trazer uma reflexão sobre a relevância que o vestuário possuiu durante o verão de 1967 através de uma revisão de bibliografia. O verão de 67 , também conhecido como o verão do amor, ficou conhecido pelas manifestações espalhadas pelo mundo todo em que reuniam pessoas de diferentes lugares em busca de objetivos em comum que eram a paz, e também a valorização de elementos da natureza. Ficando evidente a inquietação dos jovens da década de 60 , isso foi refletido diretamente no vestuário do período. Portanto, os estudos aqui apresentados são sobre o comportamento dos jovens do verão de 1967, as formas de manifestações e a atuação do vestuário.
\end{abstract}

Palavras-chave: Verão do amor. Sustentabilidade. Consumo.

Resumen: La síntesis del artículo tiene como objetivo traer una reflexión sobre la relevancia que tuvo la ropa durante el verano de 1967 a través de una revisión de la literatura. El verano del 67, también conocido como el verano del amor, se hizo conocido por las manifestaciones que se extendieron por todo el mundo en las que personas de diferentes lugares se reunieron en busca de objetivos comunes que eran la paz, y también la apreciación de los elementos de la naturaleza. A medida que la preocupación de los jóvenes en los años 60 se hizo evidente, esto se reflejó directamente en la ropa de la época. Por lo tanto, los estudios presentados aquí son sobre el comportamiento de los jóvenes en el verano de 1967, las formas de las manifestaciones y el rendimiento de la ropa.

Palabras clave: Verano de amor. Sustentabilidad. Consumo.

[2] Mestranda em Memória Social e Patrimônio

Cultural.laianasilveira@gmail.com 


\section{INTRODUÇÃo}

Esta pesquisa busca trazer a importância que foi a inserção dos jovens como um novo tipo de consumidor para o vestuário durante a década de 60, e como o ato de vestir foi influenciado e utilizado durante o período. Através da interdisciplinaridade existente do campo da moda, foi possível trazer reflexões de pesquisadores de diversas áreas como sociologia, sustentabilidade e antropologia, abordando conceitos que analisam o período específico do verão do amor, no ano de 1967.

A década de 1960 foi marcada por suas mudanças, revoluções, inúmeras manifestações e também pela exaltação da juventude, consequentemente, a adaptação da sociedade aos novos tempos. É considerado como tendo sido uma experiência social inovadora e a oposição à guerra foi o gatilho para buscar valores e estilos de vida alternativos. Um novo tempo, no qual as pessoas "fariam amor, não guerra". Segundo a autora Denise Pollini (2007):

Nos E.U.A., ocorreram as manifestações contra a segregação racial liderada por Martin Luther King, contra a Guerra do Vietnã e também o movimento feminista com Betty Friedman; na França as manifestações estudantis de 1968, e no Brasil, os movimentos contra o regime militar, a partir de 1964. No campo sexual, a pílula anticoncepcional mudou a maneira como as pessoas tratavam temas como sexo, família e relacionamento afetivo. A moda teria agora de levar em conta a cultura jovem e a cultura das ruas, deveria ser acessível e transmitir os valores da liberação sexual e de uma nova alegria de viver (POLLINI, 2007, p. 67).

Foi o período em que a voz do jovem começou a ser ouvida, e a sua participação em protestos começou a ganhar força e tornar-se fundamental como é até os dias de hoje. $E$ na moda não foi diferente, o jovem foi visto como uma nova categoria de consumidor a ser analisada, era uma nova faixa etária de público, não era mais o público infantil, mas, também ainda não eram adultos.

De acordo com professor de história da moda João Braga (2004) "não se pode negar que todos esses acontecimentos 
citados, além de outros, acabaram influenciando a moda desse período tão significativo e importante para a História do século XX" (BRAGA, 2004, p. 87). Ao longo do texto, é possível identificar como acontecimentos históricos influenciam diretamente na forma de consumir e de se vestir, e como não pensar nos dias atuais. A pesquisadora Lu Catoira (2008) resume:

A magia de 1968 está sendo revista quarenta anos depois pela mídia. Foi um ano que não pode ser esquecido por ter sido de transformações radicais das sociedades. Um ano em que o foco foi o jovem e, como ele, enigmático, estranho e ambíguo. Drogas, minissaias, pílula anticoncepcional, sexo sem culpa, psicodelismo, tropicália, movimentos feminista e negro, protestos contra a Guerra do Vietnã, defesa dos direitos dos homossexuais, revoltas estudantis pelo mundo e o recrudescimento da ditadura no Brasil. A geração de jovens dos anos 50, sem qualquer ideologia ou organização, inconformada com a situação mundial do pós-guerra, com a violência gerada pela Guerra da Coréia e, no fim da década, com o fortalecimento da brutal Guerra do Vietnã, começou a questionar os valores e costumes da época (CATOIRA, 2008, p. 1).

Em cada continente começaram a surgir manifestações organizadas por jovens que afetaram o comportamento da sociedade de uma forma irreversível, a tentativa de mudar os padrões da época ganhou força. Para o jornalista e escritor francês François Baudot (2002) "as profundas reviravoltas nas camadas sociais fazem dos anos 60 um dos períodos mais decisivos de um século de moda" (BAUDOT, 2002, p. 217). Complementando a análise de Baudot (2002), Stevenson (2012) conta que:

Num tempo de turbulência, fluxo e transformação social, a moda nos anos 1960 refletiu a natureza em rápida mudança. Quem tinha visto uma ameaça nos adolescentes dos anos 1950 teve seus piores temores confirmados. Os jovens tornaram-se decisivos para o comércio e a indústria - a aprovação dos pais perdeu a prioridade que um dia teve (STEVENSON, 2012, p. 172). 
$E$ foi nesse momento que os jovens entraram para a história da moda, não mais vestindo roupas de crianças, e muito menos com as roupas caretas que seus pais vestiam, existiam agora roupas com um estilo intermediário e que recebeu uma grande atenção do mercado da moda, os jovens comunicavam através do vestuário, esse novo posicionamento.

\section{UM NOVO TIPO DE CONSUMIDOR}

Nesse período de transformação comportamental, surgindo um novo grupo de consumidores que são os jovens, o mercado de moda se configura os inserido como um público alvo de importância, visto que, desejavam vestir roupas que expressassem essa forma de viver livre e deixar para trás vestimentas que lembravam as roupas de seus pais. Mackenzie (2010) afirma que:

A explosão da moda jovem e o análogo surgimento do Movimento British Boutique derivaram de uma situação socioeconômica particular. Os adolescentes compunham então uma parcela significativa da população, e a maioria deles tinha um poder aquisitivo com que seus pais jamais sonhavam quando jovens (MACKENZIE, 2010, p. 94).

O surgimento da moda jovem trouxe boutiques que contrastaram com as lojas tradicionais, trazendo peças com tendências joviais, mais acessíveis financeiramente e que mudavam rapidamente as vitrines, chamando a atenção do cliente por esse tratamento diferencial, valorizando a inclusão dos jovens e proporcionando uma nova experiência de compra.

Baudot (2002) diz que "a juventude é, daqui por diante, vivida como uma entidade, dotada de poder de compra e de um mercado que lhe é próprio" (BAUDOT, 2002, p. 188) novos comportamentos, novos posicionamentos, e o mercado da moda viu-se obrigado a repensar nos produtos a serem produzidos para essa faixa etária, que havia descoberto no vestuário, uma forma de se fazer presente e não acomodada. Mackenzie (2010) também conta que: 
Essas lojas traduziam o espírito dos libertários anos 1960 e forneciam, a preço acessível, modismos descartáveis em ambientes mais parecidos com um clube do que com uma loja de roupas. O fenômeno British Boutique foi um fenômeno essencialmente londrino, ainda que existissem bem sucedidas lojas britânicas em outras regiões - e de os Estados Unidos, depois, terem sua própria versão do movimento (MACKENZIE, 2010, p. 94).

A moda tornou-se jovem e descompromissada, diante desses consumidores com aparência de contestação manifestada, inquietos, curiosos, despidos de estereótipos, que buscaram também a igualdade de gêneros através do surgimento da moda unissex. Braga (2004) fala que:

Na segunda metade dos anos de 1960, surgiu a moda unissex, ou seja, a mesma moda tanto para ele quanto para ela. Isso tudo vai passar a ideia de um modo coletivo, comunitário, um ideal jovem que resultou numa espécie de uniformização da moda para ambos os sexos (BRAGA, 2004, p. 89).

Homens e mulheres passaram a partilhar das mesmas vestimentas, diferenciando mais nos cortes de cabelo, pois, os homens deixaram os cabelos longos como expressão de liberdade e as mulheres encurtaram seus cabelos de maneira que as deixaram levemente masculinizadas. Em outro momento João Braga (2011) cita a questão do surgimento do movimento hippie e que eles também defenderam o estilo da moda unissex. Braga (2011) cita que:

A atitude de repulsa do jovem ocidental contra a guerra faz surgir o movimento hippie com sua linguagem visual de contestação revelada em cabelos despenteados, roupas de aspectos artesanais, estampas floridas e muito "paz e amor" [...] A vida comunitária dos hippies favorece a unificação de gêneros na moda, motivando o surgimento do conceito da moda unissex (BRAGA, 2011, p. 69).

E foi então, no final dos anos de 1960 que o vestuário antiautoritário e de protesto assumiu essa forma hippie, com 
uma postura mais desleixada e livre, liberal até demais para os padrões da época, colocando em pauta assuntos como a liberdade com relação a sexo e drogas, e através de textos favoráveis a libertação que segundo Mendes (2003) "tiveram uma influência formadora sobre muitas jovens com consciência da moda e consciência social" (MENDES, 2003, p. 165) e começaram também a pensar em como ser um pouco mais correto quanto à ecologia. Mendes (2003) também diz que:

Esse espírito de "volta à terra" alimentou o crescente movimento ecológico e foi um dos pontos de partida para uma importante revigoração do artesanato nos Estados Unidos e no Reino Unido [...] Produtos de beleza e alimentos naturais eram vistos como a alternativa saudável aos produtos com aditivos químicos e coincidiram com o nascimento da cultura da boa forma (MENDES, 2003, p. 196).

E através dos hippies e de suas roupas, pode-se observar a valorização dos detalhes artesanais, patchworks, bordados e aplicações, maneiras mais conscientes e naturais de tornar suas peças exclusivas, e é visto hoje em dia cada vez mais a priorização que consumidores conscientes dão para esses pequenos detalhes na moda.

Principalmente, nesse período em que o cenário da moda atual, perante uma pandemia, vive de incertezas assim como as demais áreas da economia. Desde as marcas locais até as grandes lojas, todos vivenciando de forma simultânea esse período caótico e como essa crise sanitária pode atingir diretamente todas as cadeias que compõem a moda.

\section{O FENÔMENO DA MODA}

A moda é muito mais do que aquele look na vitrine do shopping, o último lançamento da coleção de estilistas renomados e os desfiles de temporada como São Paulo Fashion Week. A moda é uma forma de comunicar, pois, ao escolhermos uma roupa para sair de casa, mesmo que inconscientemente, queremos transmitir algo. O autor Braga (2011) conta que: 
Moda é modo, é maneira, é comportamento. A origem da palavra é latina, vem de modus que quer dizer, exatamente, "modo". Falar de moda não é falar somente da maneira de vestir. $\mathrm{O}$ "está na moda" é muito mais abrangente, visto que pode estar associado à arquitetura, à decoração, a uma atitude de vida, a um hábito, a lugares etc. No entanto, quando se fala de moda, imediatamente se estabelece uma relação com as questões de se vestir num determinado padrão vigente (BRAGA, 2011, p. 15).

E foi nos anos 60 que o prêt-à-porter já estava mais que definido, difundindo-se e incorporado pelo consumo de massa, sem dúvida seu grande momento de consolidação, e para que a difusão de roupas produzidas em série tivesse uma propagação geral, a imprensa colaborou muito através de revistas e reportagens, outros fatores que contribuíram para essa difusão acontecer, segundo Braga (2011) foram:

A abertura da "Casa Dior", nos EUA, em 1948, com o prêtà-porter de luxo [...] A definição das épocas de lançamento do prêt-à-porter em Paris (fevereiro e agosto), em 1955, com a revista francesa Jardins de Mode [...] A criação da primeira consultoria em estilo para a indústria, em 1965 [...] os novos criadores de moda, a partir do fim dos anos 1960 e início dos anos 1970, chamados de "estilistas" e não mais "costureiros", valorizando e popularizando a moda por intermédio da influência de rua (BRAGA, 2011, p.38).

Desse período em diante, a moda seguiu um rumo que jamais seria imaginado pela sociedade, não se era levado em consideração o que a pessoa vestia para distinguir a qual classe ela pertencia, este conceito estava ficando no passado que os jovens não queriam relembrar, Baudot (2002) comenta que "antigamente, não seguir a linha dominante da moda indicava que se era pobre. A partir dos anos 60, isso significa muito claramente que se é livre" (BAUDOT, 2002, p. 188). Braga (2004) também afirma que:

O visual de contestação dos jovens manifestou-se em uma espécie de popularização na maneira de se vestir, isto é, adotando até mesmo um aspecto mais pobre, especialmente os estudantes. A rebeldia foi a ordem da época, e a 
semelhança das roupas impedia classificar as pessoas em diferentes classes sociais. Esses jovens se rebelavam contra a vida de seus respectivos pais, contestando-os e agredindo-os com um visual inusitado (BRAGA, 2004, p.89).

A moda dessa época também possuiu algumas especificidades que mudava de acordo com cada região, encontrando na França uma moda mais refinada, sendo o oposto da moda britânica e norte-americana, Braga (2004) ressalta que "a moda ganhou algumas identidades com relação aos países de sua origem; a francesa sendo um pouco mais sofisticada; ao passo que a norte-americana e a inglesa, com maiores semelhanças, sendo mais contestadoras" (BRAGA, 2004, p. 87).

$E$ é nesse momento que o jeans firma-se na moda jovem, agora é a vez do jeans, da camiseta básica e do tênis, look carregado de simplicidade e conforto, e que muitos intervinham de forma manual para criar o seu diferencial, Braga (2004) conta que "o jeans não pode ser esquecido como a grande afirmação da moda jovem, não só em seus modelos tradicionais como também nos novos, com inúmeras intervenções modernas à sua época" (BRAGA, 2004, p. 87), e vemos a presença forte da usabilidade do jeans pela sociedade até os dias atuais.

\section{SUSTENTABILIDADE E A MODA}

Não é de hoje que o consumo consciente, os conceitos de sustentabilidade aplicados à produção de moda e a procedência da mão de obra são fatores de grande importância que o consumidor tem levado em consideração na hora da compra de um produto, pensamentos como em quais condições essa roupa foi produzida e será que essa peça possui um efeito menos negativo ao meio ambiente do que a outra peça são questionamentos que estão se tornando mais recorrentes. Gwilt (2014) comenta que:

Foi durante as décadas de 1960 e 1970 (quando os ambientalistas passaram a dar voz às suas preocupações 
acerca do impacto e da devastação provocados no meio ambiente pela sociedade consumista) que surgiu o interesse em se descobrir abordagens mais sustentáveis para a produção e o consumo (GWILT, 2014, p. 19).

Nos anos 60, não só no Brasil como no mundo todo teve o início das preocupações referentes à produção e consumo e quais seriam os danos ao meio ambiente, além de surgir essa preocupação do consumidor com o meio ambiente, e a conscientização de que alguns processos da indústria têxtil eram extremamente agressivos a natureza devido à grande quantidade de compostos químicos usados e descartados inadequadamente, houve também o surgimento do mercado justo, conhecido como Fair Trade, que levava em consideração a procedência da mão de obra do produto, e a preocupação com as condições de trabalho da classe produtora. Segundo Berlim (2012):

Nos anos 60, a consciência do consumidor europeu sobre a exploração de trabalhadores nos países em desenvolvimento ao redor do mundo fez surgir uma grande tendência chamada Fair Trade - Mercado Justo. A tendência transformou-se em movimento e hoje em dia o Fair Trade é considerado uma das maiores e mais importantes ferramentas da sociedade. A atuação do movimento mercado justo é bastante ampla, cobrindo desde o pequeno artesão até as grandes cooperativas, mas o seu foco principal recai sobre comunidades em situações desfavoráveis, em geral situadas em países pobres (BERLIM, 2012, p. 51).

Mas ainda existem muitos indivíduos na sociedade que apenas consomem sem pensar, sem se perguntar se realmente necessitam daquele produto, sem questionar a procedência do produto, e este é um ótimo período de parar para refletir sobre o que se tem dentro do guarda-roupa, através do isolamento social imposto nos dias atuais, evidentemente a sociedade tem passado mais tempo dentro de suas casas, e porque não analisar o que há nos armários, identificar 
se existem excessos, se há a necessidade real de consumir mais um produto de vestuário.

De acordo com Svendsen (2010), "o consumo funciona como um tipo de entretenimento. É um meio cada vez mais usual de combater o tédio" (SVENDSEN, 2010, p. 129), essa forma de pensamento não tem mais espaço na atualidade, o mundo não suporta mais consumidores que pensem dessa forma, através de reflexões e pequenas mudanças diárias, no final será possível identificar uma grande mudança comportamental positiva. Berlim (2012) ressalta que:

É pouco provável que ao comprar uma camiseta de algodão convencional, o consumidor pense que está comprando um produto que, até chegar às suas mãos, consumiu 160 gramas de agrotóxicos, uma determinada quantia de energia e que causou danos sérios ao solo, à água e àqueles que trabalharam no cultivo do algodão. Tampouco sabe que ele estará gerando novos impactos ambientais cada vez que sua camiseta for lavada e passada (BERLIM, 2012, p. 32).

Porém, cabe ao consumidor assumir a responsabilidade de suas compras e buscar as devidas informações, Berlim (2012) fala que "cabe ao consumidor ter a atenção necessária para buscar informação correta sobre cada produto e ser consciente da força de suas escolhas" (BERLIM, 2012, p. 64).

O meio ambiente possui intervenção de forma negativa abusivamente e já passou da hora de reverter essa situação, quanto mais for mencionando sobre os fatos já existentes como o da poluição da indústria têxtil, e repetir essas informações quantas vezes for preciso para conscientizar um número maior de pessoas, deve ser feito. Berlim (2012) afirma que:

A produção têxtil foi uma das atividades mais poluidoras do último século e foi tema de várias pesquisas que recaíram em especial sobre seus principais impactos: a contaminação de águas e do ar. Além de demandar muita energia na produção e transporte de seus produtos, a indústria têxtil polui o ar com emissões de gases de efeito estufa; as águas com as químicas usadas nos beneficiamentos, tingimentos e irrigação de plantações; e o solo, com pesticidas de alta toxidade. 
Além disso, os resíduos que permanecem nos produtos podem contaminar quem usa (BERLIM, 2012, p. 33).

É um processo demorado de conscientização do consumidor que vem acontecendo, pois só nos anos 90 chegou-se a conclusão de que não seria avaliando os danos causados pela indústria que esse impacto teria sua diminuição, e sim através do consumidor, Berlim (2012) fala que "a partir da década de 90 o foco das preocupações, discussões e pesquisas passou do processo industrial para esfera do consumo" (BERLIM, 2012, p.33), e já existe um tipo de consumidor que vem valorizando a questão de que ele como um único indivíduo precisa consumir de maneira que agrida menos o ambiente, e que ele precisa compartilhar desse pensamento com o número máximo de pessoas, precisa tornar-se um pensamento automático do mesmo jeito que fechamos a torneira enquanto ensaboamos a louça, do mesmo jeito que tomamos um banho rápido para economizar na água pelo bem do planeta, e não para que fim do mês a conta seja mais barata, esse consumidor já é sabedor que o barato sai caro em todos os aspectos. Segundo Berlim (2012):

A reflexão que nas últimas duas décadas vem ganhando
espaço nas pesquisas gira em torno do consumo
absolutamente excessivo e aparentemente infindável
de recursos naturais finitos e da falta de cuidado e
parcimônia no uso dos recursos não renováveis, ou
ainda não totalmente renováveis, como a água, o solo, o
petróleo, a fauna e a flora. Como a produção de têxteis
está diretamente ligada à moda, uma poderosa indutora
de consumo, ela pode ser considerada uma das maiores
degradantes desses recursos (BERLIM, 2012, p. 33).

Nos últimos anos houve uma grande mudança em torno da sociedade, tornando-a sociedade de consumo, porém, o papel que o consumo desenfreado vem desempenhando precisa parar e ser repensado, levando em consideração o futuro do meio ambiente, é insustentável o modelo atual de consumo em massa. Crane (2011) aponta que: 
Os ambientalistas sustentam que é necessária uma mudança importante na natureza do consumo, no sentido de que os produtos sejam produzidos de modo a proteger o ambiente e conservar os recursos, não de moda que a obsolescência dos bens de consumo seja o objetivo principal da produção e consumo dos produtos. $\mathrm{O}$ significado de consumo para o consumidor deve mudar radicalmente. As bases sobre as quais os consumidores constroem suas identidades sociais através do consumo devem ser reavaliadas (CRANE, 2011, p. 229).

Existem alguns tipos de consumidores que são classificados de acordo com seu estilo de compra, há o consumidor político, consumidor este que pensa nos danos que podem ser causado ao ambiente de acordo com cada compra que ele efetuar, o consumo político pode ser identificado por diversos tipos, trago os três principais que mais se encaixam nessa pesquisa. Crane (2011) diz que existe:

Consumo ético, em que os bens são produzidos de modo
ético, não causam danos às pessoas ou aos animais;
consumo de comércio justo, em que os bens são adquiridos
de produtores de países menos desenvolvidos a preços
que permitem que vivam de modo decente e obtenham um
lucro razoável; e consumo verde, em que os consumidores
tentam selecionar bens produzidos por meio de formas
que respeitem o ambiente e que sejam descartados de
modo similar, por meio de reciclagem e outros tipos de
descarte ambientalmente favoráveis (CRANE, 2011, p. 232).

Ou seja, esses tipos de consumidores estão cada vez mais estimulados e entusiasmados no reconhecimento de que suas escolhas na hora da compra não são mais pessoais, e sim, que possuem consequências sociais e ambientais. Segundo Marchand (2005), “o objetivo do consumo responsável é a criação de uma sociedade mais humana e duradoura, com base nos valores da igualdade, solidariedade e frugalidade" (MARCHAND apud CRANE, 2011, p. 233), e é preciso que esse tipo de pensamento dissemine-se para evitar que os danos ao ambiente continuem sendo causados sem supervisão, sem reparação e sem minimizar. 
De acordo com Crane (2011), "o objetivo da moda ética não é reduzir ou eliminar o consumo de vestuário, mas substituir os bens de consumo por produtos menos prejudiciais ao ambiente, tanto social quanto materialmente" (CRA$\mathrm{NE}, 2011$, p. 239), e através de alguns princípios fundamentais do movimento de moda sustentável que isso poderá ser possível, incluir a reutilização de roupas de segunda mão, o garimpo, a reciclagem e as reformas que podem ser feitas a partir destas peças. Existem vários R's quanto ao desenvolvimento sustentável, cada um com sua importância, Berlim (2012) destaca três deles:

Reduzir: diminuir o consumo de recursos naturais na forma de matérias-primas e energia, reduzindo assim a quantidade de descarte e poupando os recursos; Reutilizar: usar novamente os produtos, dando a eles novas funções ou não; Reciclar: retornar o que foi utilizado ao ciclo de produção (BERLIM, 2012, p. 136).

Além desses três princípios da sustentabilidade, existe também outra prática que vem firmando-se no meio da moda chamada de upcycling, que Berlim (2012) explica, "o upcycling se fundamenta no uso de materiais cuja vida úteis estejam no fim, por obsolescência real ou percebida na forma, função ou materialidade, valendo-se deles para a criação de outros" (BERLIM, 2012, p. 137), ou seja, pode-se garimpar peças em brechós, ou selecionar peças pessoais que estão em desuso e desmanchá-las reaproveitando o tecido e criando uma nova peça através de uma antiga, podendo misturar tecidos e aviamentos. Para Queiroz (2014):

Se o objeto for reciclado, reutilizado, reaproveitado ou ressignificado, provavelmente imprimir-se-á um novo valor de uso ao objeto. Ao ser simplesmente descartado no meio ambiente, sem nenhum tipo de reutilização, este objeto não só perde o seu valor de uso e troca como se transforma num produto marginal: lixo. (QUEIROZ, 2014, p. 62). 
É isso que é buscado muito na formação de um designer de moda, solucionar problemas como enxergar através de um objeto a forma de ressignificar ele agregando um novo valor. Segundo Salcedo (2014):

Qualquer pessoa que já tenha cortado e confeccionado uma peça de roupa sabe muito bem que, depois de cortar o molde sobre o tecido escolhido, sobram muitos pedaços de pano. Esses pedaços não serão incorporados à peça e, por serem muito pequenos e terem formas complicadas, em geral, são simplesmente descartados, transformando-se em resíduos pré-consumo, que, com certeza, vão terminar em um depósito de lixo. 0 design de moda sem resíduos tem como objetivo reduzir essas perdas e, eventualmente, eliminálas por completo. Uma forma fácil de minimizar esses resíduos é incorporando-os à peça para reforçar aquelas partes que costumam ser mais propensas ao desgaste, como, por exemplo, os cotovelos (SALCEDO, 2014, P. 44).

E através do upcycling, pode-se agregar as peças retalhos de sobras, ajudando a minimizar o descarte de pedaços de tecidos que já não seriam mais utilizados, visando sempre, por qualquer método, a diminuição do efeito negativo ao meio ambiente em qualquer etapa do mercado de moda.

\section{CONSIDERAÇÕES FINAIS}

Através das descobertas realizadas por meio da pesquisa bibliográfica, foi compreendido que as mudanças ocorridas no período da década de 1960 desencadearam uma liberdade maior para que houvesse manifestações, não só sobre o direito dos jovens de se vestirem de forma diferente dos pais, mas também, quanto a assuntos sociais que dizem respeito aos direitos das mulheres, ao casamento gay, ao uso de drogas e bebidas alcoólicas.

A busca pela paz através do fim da guerra do Vietnã e também a procura pela conscientização das pessoas, do que o planeta estava tornando-se a partir daquele momento, e que era necessário enxergar que em algum momento os recursos iriam terminar, foram marcos históricos que afetaram diretamente o comportamento e o consumo. 
Ao longo deste período e de suas inúmeras manifestações, a moda conseguiu ter grandes mudanças através da criatividade utilizada pelos jovens, e o consumidor trouxe uma nova forma de enxergar os produtos que não eram tão valorizados, como as roupas esquecidas em brechós que foram resgatadas, roupas em desuso nos roupeiros que foram restauradas, essa nova cultura de fazer a mão, de dar um toque especial e único, surgiu nesse momento como um grito de liberdade.

Ressalta-se também a importância da sustentabilidade e do consumo consciente que desde aquele período vinha ganhando espaço, e hoje em dia possui grande importância devido à vida de excessos que os consumidores levam. Evidenciando a importância de valorizar os produtores locais, o artesanal e a matéria-prima sustentável.

Por fim, cabe a nós como integrantes de uma sociedade, refletirmos neste período tão conturbado que o mundo vive, como podemos fazer a diferença. Estarmos em constante reflexão e evolução, aprimorar os processos que cabem a nós serem realizados, minimizar o impacto do nosso consumo e descarte ao meio ambiente, identificar o que realmente é importante ter espaço nas nossas vidas, dentro das nossas casas, em nossos guarda-roupas, qual vestuário nos identifica e o que queremos comunicar através dele.

\section{REFERÊNCIAS BIBLIOGRÁFICAS}

BAUDOT, François. Moda do século. São

Paulo: Editora Cosac Naify, 2002.

BERLIM, Lilyan. Moda e sustentabilidade:

uma reflexão necessária. São Paulo: Editora

Estação das Letras e Cores, 2012.

BRAGA, João. História da moda: uma narrativa.

São Paulo: Editora Anhembi Morumbi, 2004. 
BRAGA, João. Reflexões sobre a moda. v. 1. 5 ed.

São Paulo: Editora Anhembi Morumbi, 2011.

BRAGA, João. Reflexões sobre a moda. v. 2.3 ed.

São Paulo: Editora Anhembi Morumbi, 2011.

CATOIRA, Lu. 1968: A construção da estética jovem no cotidiano da contracultura e dos ideais de liberdades políticas, comportamentais, éticas e sexuais. $4^{\circ}$ Colóquio de moda $\square 1^{a}$ edição internacional, Novo Hamburgo, 2008.

CRANE, Diana. Ensaios sobre a moda, arte e globalização

cultural. São Paulo: Editora Senac São Paulo, 2011.

GWILT, Alison. Moda Sustentável: guia prático. Tradução Márcia Longarço. -- 1. ed. I São Paulo: Gustavo Gili, 2014.

MACKENZIE, Mairi. Ismos: para entender a moda. São Paulo: Editora Globo, 2010.

MENDES, Valerie D. A moda do século XX. São

Paulo: Editora Martins Fontes, 2003.

POLLINI, Denise. Breve história da moda.

São Paulo: Editora Claridade, 2007.

STEVENSON, Nj. Cronologia da moda: de Maria Antonieta a Alexander McQueen. Rio de Janeiro: Editora Zahar, 2012.

QUEIROZ. Leila. L. Utopia da sustentabilidade

e transgressões no design. Rio de

Janeiro: Editora 7 Letras, 2014.

SALCEDO, Elena. Moda ética para um futuro

sustentável. Espanha: Editora GGili, 2014

SVENDSEN, Lars. Moda: uma filosofia. Rio

de Janeiro: Editora Zahar, 2010. 